\title{
Longitudinal Course of Agitation and Aggression in Patients with Alzheimer's Disease in a Cohort Study: Methods, Baseline and Longitudinal Results of the A3C Study
}

\author{
A. De Mauleon ${ }^{1}$, J. Delrieu ${ }^{1}$, C. Cantet ${ }^{1}$, B. Vellas ${ }^{1}$, S. Andrieu ${ }^{1}$, P.B. Rosenberg², C.G. Lyketsos ${ }^{2}$, \\ M. Soto Martin ${ }^{1}$ \\ 1. Gérontopole, INSERM U 1027, Alzheimer's Disease Research and Clinical Center, Toulouse University Hospital, Toulouse, France; 2. Department of Psychiatry \\ and Behavioral Sciences, Johns Hopkins Bayview, Johns Hopkins University, Baltimore, United States; On behalf of the A3C study group: L. BORIES, A. ROUSTAN, \\ Y. GASNIER, S. BORDES, M.N. CUFI, F. DESCLAUX, Y. GASNIER, V. FELICELLI, N. GAITS, T. UGUEN, P. TESTE, M. PERE-SAUN, J.F. PUCHEU, S. BORDES, J.P.
} SALLES.

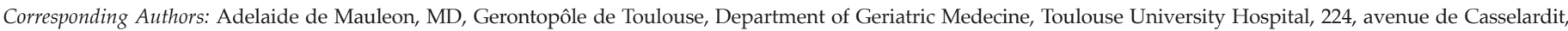
31059 TOULOUSE Cedex 9, France, Phone : +33.5.61.77.64.26, Fax : +33.5.61.77.64.78, E-mail: demauleon.a@chu-toulouse.fr

\begin{abstract}
BACKGROUND: To present methodology, baseline results and longitudinal course of the Agitation and Aggression in patients with Alzheimer's Disease Cohort (A3C) study.

OBJECTIVES: The central objective of A3C was to study the course, over 12 months of clinically significant Agitation and Aggression symptoms based on validated measures, and to assess relationships between symptoms and clinical significance based on global ratings.

DESIGN: A3C is a longitudinal, prospective, multicenter observational cohort study performed at eight memory clinics in France, and their associated long-term care facilities.

SETTING: Clinical visits were scheduled at baseline, monthly during the first 3 months, at 6 months, at 9 months and at 12 months. The first three months intended to simulate a classic randomized control trial 12-week treatment design.

PARTICIPANTS: Alzheimer's Disease patients with clinically significant Agitation and Aggression symptoms lived at home or in long-term care facilities.

MEASUREMENTS: Clinically significant Agitation and Aggression symptoms were rated on Neuropsychiatric Inventory (NPI), NPI-Clinician rating (NPI-C) Agitation and Aggression domains, and Cohen Mansfield Agitation Inventory. Global rating of agitation over time was based on the modified Alzheimer's Disease Cooperative Study-Clinical Global Impression of Change. International Psychogeriatric Association "Provisional Diagnostic Criteria for Agitation", sociodemographics, non-pharmacological approaches, psychotropic medication use, resource utilization, quality of life, cognitive and physical status were assessed.

RESULTS: A3C enrolled 262 AD patients with a mean age of 82.4 years ( $\mathrm{SD} \pm 7.2$ years), $58.4 \%$ women, $69.9 \%$ at home At baseline, mean MMSE score was 10.0 (SD \pm 8.0 ), Cohen Mansfield Agitation Inventory score was 62.0 (SD \pm 15.8 ) and NPI-C Agitation and Aggression clinician severity score was 15.8 ( $\mathrm{SD} \pm 10.8$ ). According to the International Psychogeriatric Association agitation definition, more than $70 \%$ of participants showed excessive motor activity $(n=199,76.3 \%)$ and/or a verbal aggression $(n=199,76.3 \%)$ while $115(44.1 \%)$ displayed physical aggression. The change of the CMAI score and the NPI-C Agitation and Aggression at 1-year follow-up period was respectively -11.36 (Standard Error $(S E)=1.32 ; p<0.001$ ) and -6.72 $(\mathrm{SE}=0.77 ; \mathrm{p}<0.001)$
\end{abstract}

Received August 24, 2020

Accepted for publication November 2, 2020
CONCLUSION: Little is known about the longitudinal course of clinically significant agitation symptoms in Alzheimer's Disease about the variability in different outcome measures over time, or the definition of a clinically meaningful improvement. A3C may provide useful data to optimize future clinical trials and guide treatment development for Agitation and Aggression in Alzheimer's Disease.

Key words: Agitation/aggression, dementia, cohort, validated measurements, trials.

\section{Introduction}

$\Gamma$ he syndrome of agitation and aggression (A/A) in Alzheimer's disease (AD) encompasses a range of affective, verbal or motor disturbances such as restlessness, cursing, aggression, hyperactivity, combativeness, wandering, repetitive calling out, irritability and disinhibition (1). A/ A occurs in as many as $29 \%(2,3)$ of people with AD living at home, and up to $40-60 \%$ of those living in long term care facilities (LTCF) (4). A/A is among the most prevalent, persistent and disturbing neuropsychiatric syndrome (NPS). Its severity and frequency increase with disease progression (4). Moreover, A/A has major adverse consequences for patients, families and health care systems including worse quality of life for patients and their caregivers (5), greater disability with earlier institutionalization (6), accelerated transition from prodromal $\mathrm{AD}$ to dementia (7), accelerated transition from mild dementia to severe dementia or death (8) and higher health care costs (9). Thus, the management of A/A is a major priority in caring for patients with $\mathrm{AD}$.

Currently the management of A / A remains a challenge for clinicians and caregivers due to the lack of safe and efficient medications as well as due to the difficulty of implementing best evidence non-pharmacological approaches in "real life" clinical setting (10). Although, 
medication development for treatment of A/A has seen advances in recent years, major methodological questions remain $(11,12)$. In part, this stems from limited natural history data about generalizable A/A cohorts: most data come from research whose main objective was to study cognitive and functional parameters (e.g., 13), in which patients with significant NPS were excluded or where NPS were inadequately quantified (2). Hence, for the most part these studies have been inadequate to describe the natural evolution of $\mathrm{A} / \mathrm{A}$ over time or to determine associated clinical characteristics of NPS. Further, none investigated the variability of A/A measures, variances inherent in these measures, or factors influencing this variability, which are issues crucial to trial design and interpretation of this results.

We hypothesized that $\mathrm{A} / \mathrm{A}$ in $\mathrm{AD}$ has a predictable course and associated factors, and that a longitudinal prospective observational survey specifically assessing $\mathrm{A} / \mathrm{A}$ in patients with $\mathrm{AD}$ would provide useful data for treatment development. The overarching aim of the Agitation and Aggression in patients with Alzheimer's Disease a Cohort (A3C) study was to assess the evolution and longitudinal course of $\mathrm{A} / \mathrm{A}$ in patients with $\mathrm{AD}$.

The central objective was to study the natural course of symptoms in patients with clinically significant A/A over 12 months of follow-up, with special attention to the first three which is a commonly used duration for NPS trials.

Secondary objectives included estimating the minimal clinically important differences (MCID) in outcomes and assessing the variance of $\mathrm{A} / \mathrm{A}$ symptoms over time.

\section{Methods}

\section{Design}

A3C is a longitudinal prospective multicenter observational cohort study performed at eight memory clinics from southwest France and their associated LTCF: Castres, Foix, Lannemezan, Lavaur, Lourdes, Montauban, Tarbes and Toulouse. Toulouse University Hospital was the coordinating center. Clinical visits $(V)$ were scheduled at baseline (V1), monthly during the first 3 months of follow-up (V2 to V4), at 6 months (V5), at 9 months (V6) and at 12 months (V7) during a 1-year follow-up period. The first three months of $\mathrm{A} 3 \mathrm{C}$ were designed to simulate a classic randomized controlled trial 12-week treatment design. Participants were recruited between December 2014 and August 2017. The last follow up visit took place in June 2018.

\section{Participants/population}

Participants were men and women, aged 60 years and older, with possible Alzheimer's dementia according to NIA-AA's criteria (14), with or without cerebrovascular components, and regardless of Mini Mental State
Examination (MMSE) score. Participants had clinically significant agitation defined broadly by the presence of significant symptoms on at least one of the following NPS as rated on the Neuropsychiatric Inventory (NPI): A/A, disinhibition, aberrant motor behavior and/or irritability (15). Clinically significant was defined as NPI agitation/ aggression domain score $\geq 4$ with NPI frequency score $\geq 2$ at entry. Participants also met the International Psychogeriatric Association (IPA) provisional definition of agitation in cognitive disorders (16).

1. Patients could live at home or in a LTCF. To be included, community dwelling patients had to have an identified primary caregiver, who visited at least three times a week for several hours and supervised patient's care, and was available to accompany the patient to study visits and to participate in the study. Patients living in a LTCF had lived in the facility for at least two months before inclusion. Patients were excluded if: they had other brain diseases (e.g., extensive brain vascular disease, Parkinson's disease, other dementias or traumatic brain injury), major depressive episode according to DSMIV(TR) criteria (http:/ / dsm.psychiatryonline.org/doi/ abs / 10.1176/ appi.books.9780890420249.dsm-iv-tr), or serious illness that would impair their ability to perform study assessments; the agitation or aggression was attributable to concomitant medications, active medical or psychiatric conditions; had clinically significant psychosis with a NPI domain's score (hallucinations or delusions) $\geq$ 4 or were participating in a clinical trial.

Participants and their caregivers took part in the study voluntarily: written informed consent was obtained from all patients (or legal representatives) and caregivers (for the community dwelling population). Each participant's capacity to give consent was assessed in clinical interviews by clinicians experienced in dementia research. Consent was personally provided if the participant was found to be capable. If the participant was not fully capable of consent, then it was obtained from an authorized legal representative. A3C had ethical approval and oversight from the local Institutional Review Board (Toulouse University Hospital).

\section{Institutional long-term care facilities}

In this study, an LTCF was defined as a place of communal living where care and accommodation are provided as a package by a public agency, nonprofit company or private company. LTCF included assisting living, nursing home and other long-term care facilities.

\section{Data collection}

At baseline and at every follow-up visit, data collection was performed by trained professionals with clinical experience, during to face-to-face interviews, and recorded on standardized case record form. All raters 


\begin{tabular}{|c|c|c|c|c|c|c|c|}
\hline Assessments & V1 (M0) & V2 (M1) & V3 (M2) & V4 (M3) & V5 (M6) & V6 (M9) & V7 (M12) \\
\hline Informed consent & $\mathrm{x}$ & & & & & & \\
\hline NPI and IPA provisional definition of agitation & $\mathrm{x}$ & & & & & & \\
\hline Socio demographics and home aid* & $\mathrm{x}$ & $\mathrm{x}$ & $\mathrm{x}$ & $\mathrm{x}$ & $\mathrm{x}$ & $\mathrm{x}$ & $\mathrm{x}$ \\
\hline Medical history & $\mathrm{x}$ & & & $\mathrm{x}$ & $\mathrm{x}$ & $\mathrm{x}$ & $\mathrm{x}$ \\
\hline All medications & $\mathrm{x}$ & & & & & & \\
\hline Ongoing psychotropic medication and anti-dementia treatments & $\mathrm{x}$ & $\mathrm{x}$ & $\mathrm{x}$ & $\mathrm{x}$ & $\mathrm{x}$ & $\mathrm{x}$ & $\mathrm{x}$ \\
\hline Clinical examination & $\mathrm{x}$ & $\mathrm{x}$ & $\mathrm{x}$ & $\mathrm{x}$ & $\mathrm{x}$ & $\mathrm{x}$ & $\mathrm{x}$ \\
\hline CMAI & $\mathrm{x}$ & $\mathrm{x}$ & $\mathrm{x}$ & $\mathrm{x}$ & $\mathrm{x}$ & $\mathrm{x}$ & $\mathrm{x}$ \\
\hline Modified ADCS-CGIC & & $\mathrm{x}$ & $\mathrm{x}$ & $\mathrm{x}$ & $\mathrm{x}$ & $\mathrm{x}$ & $\mathrm{x}$ \\
\hline MMSE & $\mathrm{x}$ & & & $\mathrm{x}$ & $\mathrm{x}$ & $\mathrm{x}$ & $\mathrm{x}$ \\
\hline Katz's ADL & $\mathrm{x}$ & & & $\mathrm{x}$ & $\mathrm{x}$ & $\mathrm{x}$ & $\mathrm{x}$ \\
\hline One leg balance test & $\mathrm{x}$ & & & $\mathrm{x}$ & $\mathrm{x}$ & $\mathrm{x}$ & $\mathrm{x}$ \\
\hline QoL-AD (Logsdon scale) & $\mathrm{x}$ & & & $\mathrm{x}$ & $\mathrm{x}$ & $\mathrm{x}$ & $\mathrm{x}$ \\
\hline RUD & $\mathrm{x}$ & & & & $\mathrm{x}$ & $\mathrm{x}$ & $\mathrm{x}$ \\
\hline Non-pharmacological approaches & $x$ & $x$ & $x$ & $x$ & $x$ & $\mathrm{x}$ & $x$ \\
\hline
\end{tabular}

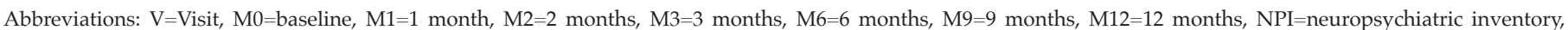

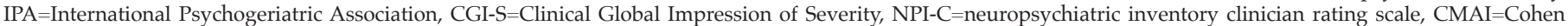

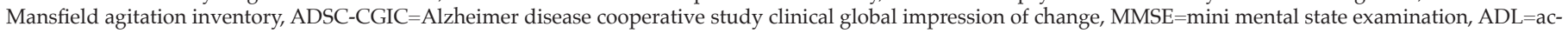
tivities daily living, QoL-AD=quality of life of patient with Alzheimer's disease (Logsdon scale), RUD=resource utilization in dementia instrument.

*if patient living at home with an identified primary caregiver

were standardized trained to perform the scales used in the study. A special standardized training was performed in all clinicians' raters for primary outcomes: mADCSCGIC, CMAI and NPI-C A/A. Visits were performed in outpatient memory clinics for community dwelling patients and their caregivers. For institutionalized patients, data were collected from the LTCF staff, in the majority of cases the same each patient's "referent staff" was interviewed each rating. Table 1 shows the investigation schedule for participants and their primary caregivers, if applicable.

\section{Demographics}

Participant age, gender, education, living arrangement and community care services were recorded using a structured questionnaire directed to patients and/or their caregivers as appropriated at baseline. The sociodemographic characteristics were recorded from the primary caregiver for patients living at home by an identified primary caregiver. Changes in living arrangement and community care services were noted at each visit. Whether the patient lived in a LTCF and a dementia special care unit were both recorded.

\section{Medical characteristics}

Medical history of past and current conditions was recorded with a focus on cardio-vascular conditions, fractures, cancers, renal failure, sensory disabilities, gastro-intestinal, neurologic and psychiatric diseases. At baseline, caregiver current medical history and ongoing treatments was collected when appropriate. At each visit, clinical examination of participants was performed; changes concerning pharmacological treatments with focus on anti-dementia treatments (Donepezil, Rivastigmine, Galantamine, Memantine), other psychotropic drugs and intercurrent events (hospitalizations, falls, undernutrition) since the last visit were collected.

\section{NPS assessment}

\section{Agitation and aggression symptoms}

Agitation severity was rated by validated measures such as the A/A domain from the Neuropsychiatric Inventory (NPI) (17), the Neuropsychiatric Inventory Clinician rating (NPI-C) (18) and the Cohen Mansfield 
Agitation Inventory (CMAI) (1).

The NPI A / A domain measures frequency and severity of A / A symptoms. The identified caregiver rated the A / A NPI domain for symptoms frequency (in a 1-4 scale: occasionally [less than once per week], often [about once per week], frequently [several times per week but less than every day] or very frequently [more than once per day], respectively) and severity (in a 1-3 scale: mild, moderate and marked, respectively). The NPI's scoring yields a composite (frequency $\mathrm{x}$ severity) score of 1-12 for the domain. The NPI A/A domain also quantifies caregiver distress on a scale 0-5: none, minimal, mild, moderate, marked or extremely marked.

NPI-C (18) measures the severity of A/A based on a combined domain score of distinct agitation (13 items) and aggression (8 items) domains (NPI-C-A/A). Each NPI-C domain measures: (1) item frequency on a 1-4 scale: less than once per week, about once a week, several times per week but less than every day or more than once per day respectively, (2) item severity domain on a 1-3 scale: minimal, mild, moderate and marked respectively , (3) caregiver distress on a 0-5 scale: none, minimal, mild, moderate, marked or extremely marked, and (4) item clinician severity on a 0-3 scale: none, mild, moderate and marked, based on clinician judgement. The combined clinician severity score of both domains (agitation and aggression) ranges from 0 to 63 and is the NPI-C rating of interest in A3C. NPI-C is a clinician-rated questionnaire.

The Cohen Mansfield Agitation Inventory (CMAI) (1) is a caregiver-rated questionnaire. It quantifies the frequency of 29 behaviors exhibited by the patient on a 7 -point scale from never (1), less than once a week (2), once or twice a week (3), several times a week (4), once or twice a day (5), several times in a day (6) to several times in an hour (7) throughout the preceding 2 weeks. Total score ranged from 29 to 203. A higher score indicated more severe NPS.

The Alzheimer Disease Cooperative Study-Clinical Global Impression of Change (ADCS-CGIC) (19) is a global rating of change and was developed to assess clinically significant change in symptoms over time in AD clinical trials by experienced clinicians. The modified ADCS-CGIC agitation domain version (20) rates agitation five areas globally: mood lability, emotional distress, physical agitation, verbal aggression and physical aggression. It defines the severity of agitation from absent, not at all ill (1), to borderline ill (2), mildly ill (3), moderately ill (4), markedly ill (5), severely ill (6), or among the most extremely ill patients (7) at baseline. During follow-up, the mADCS-CGIC agitation domain rated global clinical change in agitation as: very much improved (1), much improved (2), minimally improved (3), no change (4), minimally worse (5), much worse (6), very much worse (7) compared to baseline symptoms.

The Clinical Global Impression of Severity (CGI-S) is a clinician-rated, 7-point scale that is designed to rate the severity of the subject's agitation symptoms at baseline using the investigator's judgment and past experience with the subjects who have the same symptoms (21).

The International Psychogeriatric Association (IPA) "Provisional Diagnostic Criteria for Agitation" (16), identifies three groups of agitation symptoms:

- Excessive motor activity (moving continuously, swinging, gesturing, pointing, repetitive mannerism, restless).

- Verbal aggression (screaming, speaking aloud in an excessive way, coarseness, yelling, shouting, voice bursts).

- Physical aggression (tearing, pushing, resisting, hitting, kicking people or objects, scratching, biting, throwing objects, hitting oneself, slamming doors, tearing things apart, destroying property).

\section{Other neuropsychiatric symptoms}

The NPI-C measures a total of 12 individual domains besides agitation and aggression: delusions, hallucinations, depression/dysphoria, anxiety, elation/ euphoria, apathy/indifference, disinhibition, irritability/ lability, aberrant motor behavior, sleep, appetite and eating disorders, aberrant vocalizations. Each NPI-C domain is rated as with the agitation and aggression NPI-C domains. Each NPI-C domain is included in the NPI except for aberrant vocalizations.

Psychotropic medication

Psychotropic medications were differentiated according to ACT coding as antipsychotic, antidepressant, hypnotic, anxiolytic and other drugs. All medications were recorded at each visit based on the patient's prescription drug that was verified by the physician from the memory clinic or by the nurse form the LTCF.

\section{Non-pharmacological approaches}

The study team was documenting non-pharmacologic treatments and/or approaches for A/A and were classified into three groups according their targets: (1) targeting the patient, (2) targeting the informal or professional caregiver and (3) targeting the environment. For example, caregiver supportive interventions were collected as binary variables (yes/no) such as caregiver training in education about dementia, communication skills, improving caregiver mismatch of her expectations and dementia severity and, finally, assessment or informal caregiver's burden or mood disorders. Concerning the environment, the following interventions were collected as binary variables (yes/no): improving excess/lack of stimulation, patient isolation, establishing an everyday structured routine, proposing meaningful activities adapted to the patient's abilities and tastes (10). Intervention by different health professionals was also recorded in both settings. 


\section{Non behavioral and psychological assessment}

\section{Cognitive assessment}

Time since diagnosis of AD was recorded. Cognitive impairment was rated on Mini Mental State Examination (MMSE) to evaluate orientation, memory, attention, concentration, denomination, repetition, comprehension, ability to formulate a whole sentence and to copy polygons (22). Disease severity at entry was defined as mild ( $\geq 21)$, moderate (20-15), moderately severe (14-10), or severe $(<10)$. If $\mathrm{AD}$ biomarkers in cerebrospinal fluid were measured to help the diagnosis was noted.

\section{Functional evaluation}

Physical impairment was based on Katz's activities of daily living (ADL) scale (23). This is a 6-item scale with a total score ranging from 0 from 6 . A higher score indicates less functional impairment. One leg balance test was performed to evaluate risk of falls. The risk of fall increases if the one leg balance test is less than or equal to 5 seconds (24).

\section{Quality of life}

Quality of life of was based on QoL-AD (25). This scale evaluates 13 items self- or caregiver-report: physical health, energy, mood, living situation, memory, family, marriage, friends, self, ability to do chores, ability to do things for fun, money and life as a whole. Each item is rated on a 1-4 score scale: poor, fair, good, excellent respectively. Total score ranges from 13 to 52. A higher score indicated a better quality of life.

\section{Resource Utilization in Dementia}

Health care resources consumed by patients with $A D$ were assessed with the Resource Utilization in Dementia (RUD) instrument (26). This questionnaire collected data about medical resources (inpatient stays, outpatient visits and medication), community care services (district nurse, home help, day care, transportation, meals on wheels), and time spent by the caregiver on ADL and instrumental ADL.

\section{Statistical analysis}

To describe the characteristics at baseline, we presented frequencies and percentages for the qualitive variables, and the mean \pm Standard Deviation (SD) for the quantitative variables. To compare the characteristics of participants between patients in LTCF vs patients at home at baseline we used the Chi-square test or the Fisher's exact test (if theorical frequency $<5$ ) for the qualitative variables. For the quantitative variables, we used the Student test for Gaussian distributions and the Kruskal-
Wallis non parametric test for non-Gaussian distributions. To estimate the change from baseline of CMAI and NPIC-A/A, we used a linear mixed model with time in continuous. Mixed models included all available data (M0, M1, M2, M3, M6, M9 and M12). We included subject-specific random effects to take into account the intra-subject correlation: a random intercept to take into account the heterogeneity of the CMAI and NPI-C-A / A at baseline and a random slope to take into account the heterogeneity of the slopes between subjects. The centrespecific random intercept was not included because this term was not significant. All statistical analyses were performed using SAS software version 9.4 (SAS Institute Inc, Cary, NC).

\section{Results}

\section{Baseline characteristics of the A3C cohort}

Table 2 shows the baseline characteristics of the participants. Study patients were very elderly with mean age above 80 years and the majority were women. The greatest majority lived at home alone or with an informal caregiver. Almost two-thirds had a cardiovascular risk factor but only a minority had a psychiatric history. Based on mean MMSE most had moderate or more severe dementia of several years' duration. Fewer than half received an AD specific medication, mostly anticholinesterases, but $\sim 80 \%$ were receiving a psychotropic. The mean duration of follow-up for patients was 9.5 months (Standard Deviation (SD) \pm 4.3 ).

\section{Figure 1. Flow chart of the A3C study}

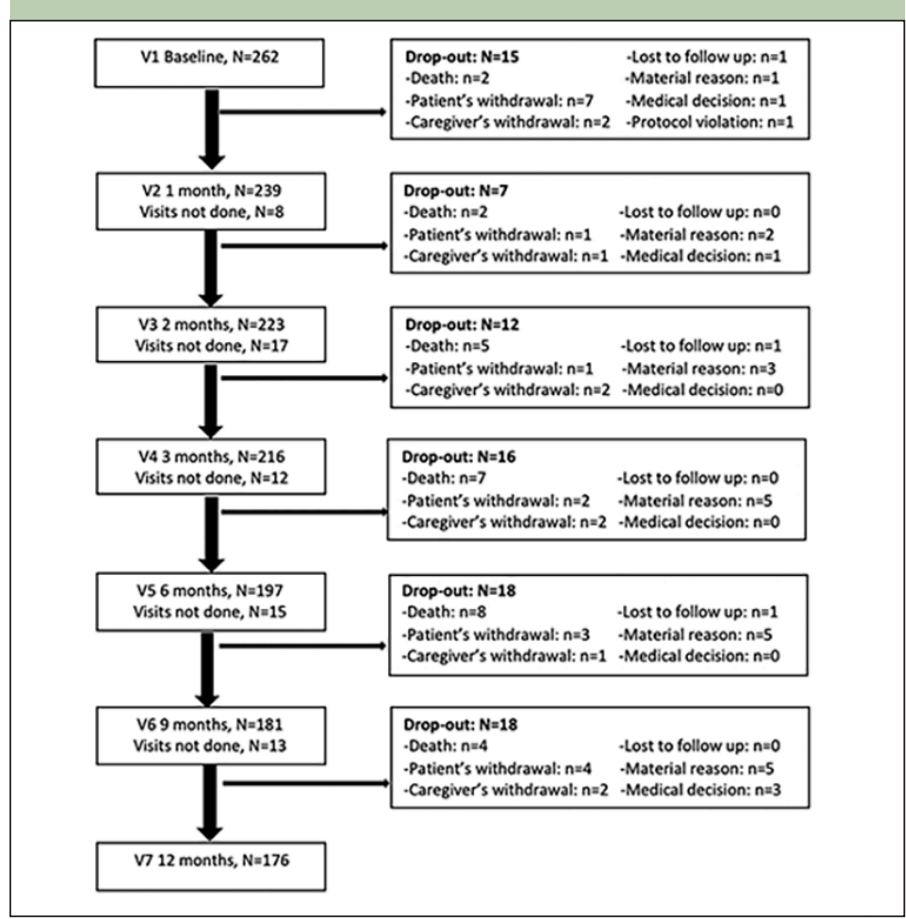

Abbreviations: $\mathrm{V}=$ Visit. 
Table 2. Baseline characteristics of the A3C cohort $(\mathrm{N}=262)$

Study population $(n=262)$

Demographic characteristics

Female, n (\%)

Age*(years)

Marital status, n (\%):

Married/cohabiting

Widowed

Never married

Divorced/separated

Living accommodation, $\mathrm{n}(\%)$ :

Home

own home, alone

own home, with spouse

own home, with relative

own home, with friend

senior residence

Long term care facilities

Level of education, $\mathrm{n}(\%)$ :

No diploma

Primary school without certificate

Primary school certificate

Secondary education, without high-school diploma

High-school diploma (Baccalaureat) or higher

Demographic characteristics of caregiver ${ }^{* *}$

Female, n (\%)

Age*(years)

Status, $\mathrm{n}(\%)$ :

Spouse

Child

Brother/Sister

Nephew/niece

Friend

Other

Only caregiver, $\mathrm{n}(\%)$

Time spent on caring* (hours/week)

Medical history

Cardio-vascular risk factors, n (\%):

Sensory disabilities, $\mathrm{n}(\%)$ :

Visual

Hearing

Neurologic diseases, n (\%):

Stroke

Epilepsy

Psychiatric diseases, $\mathrm{n}(\%)$ :

Antidementia medication, $\mathrm{n}(\%)$ :

Total
$153(58.4 \%)$

$82.4( \pm 7.2)$

$152(58.5 \%)$

$93(35.8 \%)$

$3(1.2 \%)$

$12(4.6 \%)$

$183(69.9 \%)$

$29(11.1 \%)$

$121(46.2 \%)$

$30(11.5 \%)$

$2(0.8 \%)$

$1(0.4 \%)$

$79(30.1 \%)$

$15(6.1 \%)$

$75(30.4 \%)$

$59(23.9 \%)$

$54(21.9 \%)$

$44(17.8 \%)$

$120(65.6 \%)$

$68.1( \pm 13.1)$

$103(56.3 \%)$

$67(36.6 \%)$

$3(1.6 \%)$

$3(1.6 \%)$

$1(0.6 \%)$

$6(3.3 \%)$

$93(52.0 \%)$

$67.5( \pm 51.1)$

$180(69.0 \%)$

$138(52.9 \%)$

$71(27.3 \%)$

$29(11.2 \%)$

$4(1.5 \%)$

$72(27.8 \%)$

$127(48.5 \%)$ 
Table 2 (continued). Baseline characteristics of the A3C cohort $(\mathrm{N}=262)$

\begin{tabular}{|c|c|}
\hline & Study population $(n=262)$ \\
\hline Anticholinesterases only & $67(25.6 \%)$ \\
\hline Memantine only & $56(21.4 \%)$ \\
\hline Bitherapy (anticholinesterases and memantine) & $4(1.5 \%)$ \\
\hline \multicolumn{2}{|l|}{ Psychotropics, total n (\%): } \\
\hline Total & $217(82.8 \%)$ \\
\hline Antipsychotic & $101(38.6 \%)$ \\
\hline Antidepressant & $140(53.4 \%)$ \\
\hline Anxiolytic & $140(53.4 \%)$ \\
\hline Hypnotic & $71(27.1 \%)$ \\
\hline \multicolumn{2}{|l|}{ Severity of $A D$} \\
\hline MMSE, total* & $10.0( \pm 8.0)$ \\
\hline \multicolumn{2}{|l|}{ MMSE, stage, n (\%): } \\
\hline Mild ( $\geq 20)$ & $33(13.2 \%)$ \\
\hline Moderate (10-19) & $103(41.4 \%)$ \\
\hline Severe $(<10)$ & $113(45.4 \%)$ \\
\hline Time since diagnosis of $\mathrm{MA}^{*}$ (months) & $32.8( \pm 32.5)$ \\
\hline $\mathrm{ADL}$, total ${ }^{*}$ & $3.7( \pm 1.7)$ \\
\hline \multicolumn{2}{|l|}{ AD complications in the last 3 months, $\mathrm{n}(\%)$ : } \\
\hline Weight loss & $60(22.9 \%)$ \\
\hline Gait impairment & $77(29.4 \%)$ \\
\hline Fall & $33(12.6 \%)$ \\
\hline Behavioral symptoms other than A/A & $56(21.4 \%)$ \\
\hline
\end{tabular}

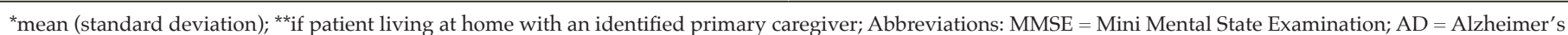
disease; $\mathrm{ADL}=$ Katz's activities of daily living scale; $\mathrm{A} / \mathrm{A}=$ agitation/aggression.

Figure 1 presents subject disposition at follow-up in detail. Of the 262 patients enrolled $86(32.8 \%)$ subjects dropped out over the 1-year follow-up. Attrition during the three first months, the critical period of A3C study, was $13.0 \%(n=34)$.

At baseline, study patients in LTCF were older $(\mathrm{p}=0.0003)$, more physically $(\mathrm{p}<0.0001)$ and cognitively $(\mathrm{p}<0.0001)$ disabled than the home-based subgroup. All types of psychotropic medications were more frequent among patients living in LTCF: antipsychotics $(\mathrm{p}=0.004)$, antidepressants $(p=0.0006)$, anxiolytics $(p<0.0001)$ and hypnotics $(\mathrm{p}<0.0001)$. However, the total score of NPI and the total score of CMAI were not significantly different between both subgroups at baseline $(p=0.31$ and $p=0.25$, respectively).

\section{Baseline characteristics of neuropsychiatric symptoms (NPS)}

By the IPA agitation definition, most participants had excessive motor activity $(76.3 \%)$ and/or a verbal aggression $(76.3 \%)$, while $115(44.1 \%)$ displayed physical aggression. Table 3 shows the characteristics of A/A ratings and other NPS in study participants.

\section{Longitudinal courses of agitation symptoms over 12 months of follow-up}

The CMAI score decreased significantly between the baseline (mean $=61.5$; [Standard Error SE \pm 1.0$]$ ), the 6 months of follow-up (V5) (mean = 50.5; [SE 11.0$])$ and the 12 months (V7) $($ mean $=50.1 ;[\mathrm{SE} \pm 1.2])$. The mean of the NPI-C-A / A clinician severity score was $15.5(\mathrm{SE} \pm 0.7)$ at baseline, $8.8(\mathrm{SE} \pm 0.6)$ at 6 months (V5) and $8.8(\mathrm{SE} \pm 0.7)$ at 12 months (V7). The change of the CMAI score and the NPI-C A / A at 1-year follow-up period was respectively -11.36 (SE=1.32; $\mathrm{p}<0.001)$ and -6.72 (SE=0.77; $\mathrm{p}<0.001)$. The figure 2 presents the change of the CMAI score and the change of the NPI-C-A/A score during the 1-year follow-up period. The figure 3 shows the variation of the modified ADCS-CGIC agitation domain version at each visit of follow-up (V2 to V7) with the modified ADCSCGIS at baseline. 
Table 3. Baseline characteristics of neuropsychiatric symptoms of the A3C cohort $(\mathrm{N}=262)$

\begin{tabular}{|c|c|}
\hline Neuropsychiatric symptoms & $\begin{array}{l}\text { Study population } \\
\qquad(\mathrm{n}=262)\end{array}$ \\
\hline \multicolumn{2}{|l|}{ IPA, definition of agitation: } \\
\hline Excessive motor activity & $199(76.3 \%)$ \\
\hline Verbal aggression & $199(76.3 \%)$ \\
\hline Physical aggression & $115(44.1 \%)$ \\
\hline \multicolumn{2}{|l|}{ NPI-C, $n(\%):$} \\
\hline Delusions & $43(16.4 \%)$ \\
\hline Hallucinations & $17(6.5 \%)$ \\
\hline Agitation & $242(92.4 \%)$ \\
\hline Aggression & $197(75.2 \%)$ \\
\hline Agitation/Aggression & $250(95.4 \%)$ \\
\hline Depression & $111(42.5 \%)$ \\
\hline Anxiety & $154(59.0 \%)$ \\
\hline Euphoria & $22(8.4 \%)$ \\
\hline Apathy & $127(48.5 \%)$ \\
\hline Disinhibition & $97(37.0 \%)$ \\
\hline Irritability & $200(76.3 \%)$ \\
\hline $\mathrm{AMB}$ & $171(65.5 \%)$ \\
\hline Sleep disorder & $110(42.2 \%)$ \\
\hline Eating disorder & $97(37.0 \%)$ \\
\hline Aberrant vocalization & $36(13.7 \%)$ \\
\hline \multicolumn{2}{|l|}{ NPI, frequency $x$ severity item $*$ : } \\
\hline Delusions & $0.5( \pm 1.3)$ \\
\hline Hallucinations & $0.2( \pm 1.1)$ \\
\hline Agitation & $7.1( \pm 4.4)$ \\
\hline Aggression & $5.3( \pm 4.7)$ \\
\hline Agitation/Aggression & $8.1( \pm 4.1)$ \\
\hline Depression & $2.9( \pm 4.2)$ \\
\hline Anxiety & $4.8( \pm 5.0)$ \\
\hline Euphoria & $0.4( \pm 1.4)$ \\
\hline Apathy & $4.4( \pm 4.8)$ \\
\hline Disinhibition & $2.8( \pm 4.5)$ \\
\hline Irritability & $6.4( \pm 4.8)$ \\
\hline AMB & $5.8( \pm 5.0)$ \\
\hline Sleep disorder & $3.5( \pm 4.8)$ \\
\hline Eating disorder & $3.2( \pm 4.6)$ \\
\hline NPI, frequency $x$ severity total score* & $42.9( \pm 18.3)$ \\
\hline \multicolumn{2}{|l|}{ NPI-C, clinician severity*: } \\
\hline Delusions & $0.5( \pm 1.4)$ \\
\hline Hallucinations & $0.2( \pm 0.8)$ \\
\hline Agitation & $10.6( \pm 7.3)$ \\
\hline Aggression & $5.2( \pm 5.1)$ \\
\hline Agitation/aggression & $15.8( \pm 10.8)$ \\
\hline Depression & $3.2( \pm 4.7)$ \\
\hline
\end{tabular}

Table 3 (continued). Baseline characteristics of neuropsychiatric symptoms of the A3C cohort $(\mathrm{N}=262)$

\begin{tabular}{|l|c|}
\hline Neuropsychiatric symptoms & $\begin{array}{c}\text { Study population } \\
(\mathrm{n}=262)\end{array}$ \\
\hline Anxiety & $5.2( \pm 6.3)$ \\
\hline Euphoria & $0.3( \pm 1.1)$ \\
\hline Apathy & $4.6( \pm 6.8)$ \\
\hline Disinhibition & $3.2( \pm 5.8)$ \\
\hline Irritability & $8.2( \pm 7.5)$ \\
\hline AMB & $4.7( \pm 5.5)$ \\
\hline Sleep disorder & $3.1( \pm 5.0)$ \\
\hline Eating disorder & $1.5( \pm 2.5)$ \\
\hline Aberrant vocalization & $0.6( \pm 1.8)$ \\
\hline NPI-C, clinician rating severity total score* & $50.5( \pm 29.3)$ \\
CMAI, total & $62.0( \pm 15.8)$ \\
\hline CGI-S, severity n $(\%):$ & \\
\hline Normal & $0(0.0 \%)$ \\
\hline Borderline mentally ill & $0(0.0 \%)$ \\
\hline Mildly ill & $32(12.2 \%)$ \\
\hline Moderately ill & $89(34.0 \%)$ \\
\hline Markedly ill & $93(35.5 \%)$ \\
\hline Severely ill & $39(14.9 \%)$ \\
\hline Among the most extremely ill & $9(3.4 \%)$ \\
\hline
\end{tabular}

*mean (standard deviation) ; Abbreviations: CGI-S = Clinician's Global Impression of Severity; NPI = Neuropsychiatric Inventory; NPI-C = Neuropsychiatric Inventory Clinician rating scale; CMAI = Cohen Mansfield Agitation Inventory; $\mathrm{AMB}=$ aberrant motor behavior; $\mathrm{A} / \mathrm{A}=$ agitation / aggression; IPA = International Psychogeriatric Association.

\section{Discussion}

Two hundred sixty-two patients with clinically significant A/A were enrolled in A3C study, most living at home, with moderate to severe dementia. At baseline, more than $70 \%$ showed excessive motor activity and/ or a verbal aggression while fewer than half displayed physical aggression. At baseline, psychotropic medication was prescribed to $80 \%$. Agitation symptoms experienced the greatest decreases during the first three months of follow-up, and A/A continued to improve through 12 months.

Concerning the specific study design of the A3C study, a monthly visit schedule during the first 3 months was chosen to address the primary aim of the A3C study. The first three months of $\mathrm{A} 3 \mathrm{C}$ intends to simulate a classic randomized control trial 12-week treatment design. Evolution, variability and associations between different outcome measures will be specifically studied during this time. Subsequently, visits every three months were chosen until the end of a year for the purposes of detecting changes in NPS in shorter periods of time. In fact, since NPS are characterized by frequent fluctuations as well as by differences in the concurrent presentation 
Figure 2. Change of the total CMAI and the total NPI-C-A / A during the follow-up (results from mixed linear models)
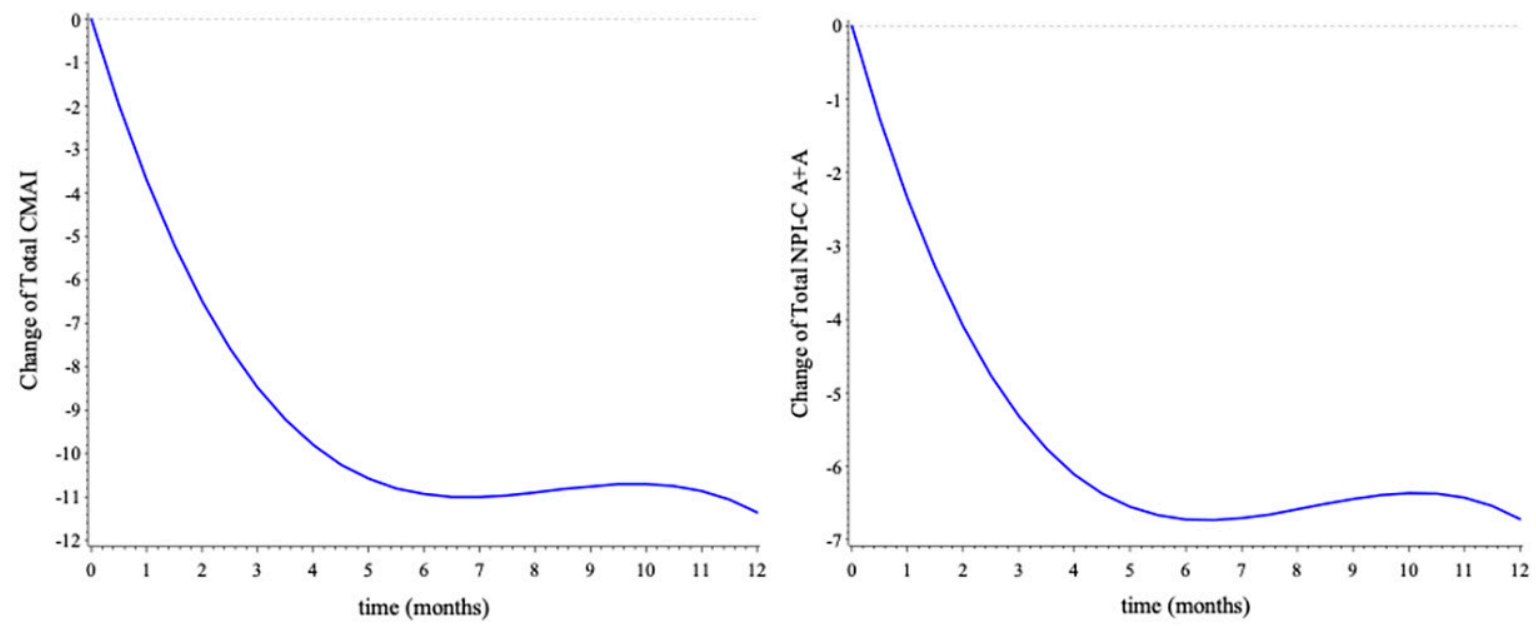

Figure 3. Comparison of the modified ADCS-CGIC agitation domain version at each visit of follow-up (V2 to V7) with the baseline (V1)

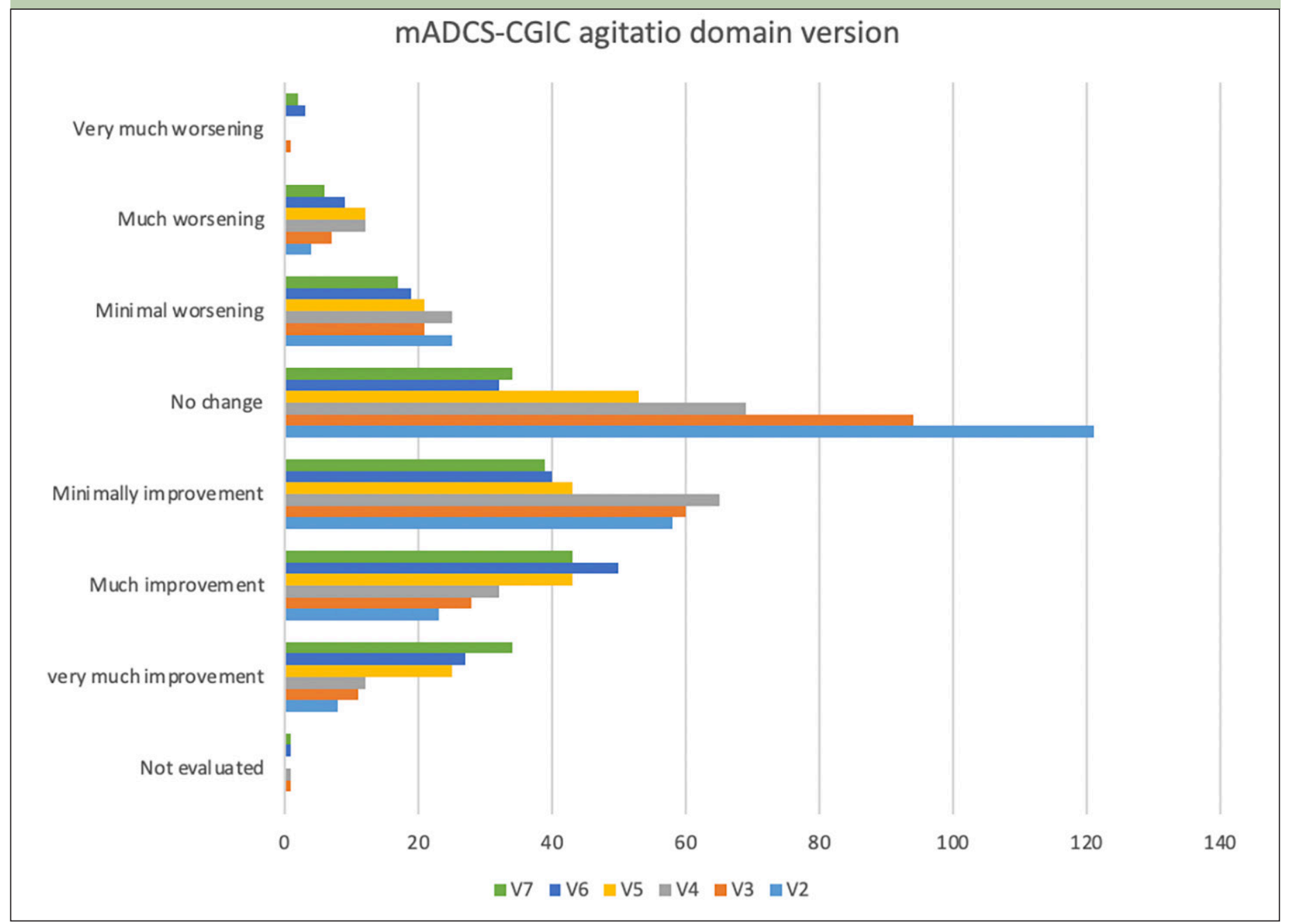

Abbreviations: $\mathrm{V}=$ Visit, $\mathrm{mADSC}-\mathrm{CGIC}=$ modified Alzheimer disease cooperative study clinical global impression of change agitation domain 
of different symptoms, shorter intervals between assessments is needed in order to better and more precisely describe their course. Further data of the A3C will help to identify different A/A trajectories based on variations in change over the time in the frequency and the severity of symptoms and their associated factors, to study the coexistence of other clinically significant NPS, and to analyze patterns, and impact of pharmacological and other non-pharmacological approaches in the management of clinically significant A/A.

A recent systematic review estimated the incidence of clinically significant agitation in nursing home patients to be $18.8 \%$ over 12 months and $36 \%$ over 4 -years (27). Several studies evaluated disease progression of agitation in AD: six studies reported an increase in severity/ frequency of agitation over time, two studies presented mixed results and one showed a decrease (27). To our knowledge, to date no study describes the course of A/A overtime in community-dwelling AD patients. Interestingly, in A3C study, a major decrease of A/ A symptoms was observed during the first 3 months of follow-up which slowly continued to decrease over the course until the end of follow-up. Certainly, the A3C cohort benefits from a management for the treatment of NPS that may include medications and/or nonpharmacological approaches that may be considered as "usual care" since no intervention was implemented in $\mathrm{A} 3 \mathrm{C}$, and as consequence, $\mathrm{A} 3 \mathrm{C}$ still studies natural history of the agitation syndrome in usual care settings. However, the specific design of $\mathrm{A} 3 \mathrm{C}$ with a follow up with short periods of time between visits, could be considered as a way of intervention similar to clinical trials. This could explain the continued decrease of agitation symptoms over time during the entire followup.

Several organizations, including the Food and Drug Administration and the European Alzheimer's Disease Consortium, have expressed interest in better characterizing NPS, such as psychosis or depression in $\mathrm{AD}$, which would be highly relevant for treating NPS in $\mathrm{AD}$ (28). Consensus diagnosis criteria for Agitation in $\mathrm{AD}$ were recently proposed (16). To our knowledge, the A3C study is the first cohort study using these criteria in a longitudinal observational study design. The whole A3C population met the criteria for A/A syndrome based on IPA criteria definition: three quarters showed excessive motor activity and/or verbal aggression and physical aggression occurred in a lesser patient. Gaining clarity about the clinical entity of A/A is of great importance, since its different phenotypes may delineate underlying disruptions in specific neuronal regions and/or circuitry and shed light on etio-pathogenesis enhancing the development of pharmacologic or non-pharmacologic treatments for specific A/A phenotypes. Aggressive behavior may respond to a drug differently than excessive motor activity behavior. Moreover, improving knowledge about pathogenesis pathways of A/A may lead to the study of biomarkers and to the increase of the use of biomarkers to maximize the productivity of clinical trials for NPS (12).

Of the common NPS, the natural history of A/A (phenomenology, course and associated factors) in $\mathrm{AD}$ is least well understood resulting in the lack of a "gold standard" efficacy outcome in therapeutics research development. In fact, little is known about the natural course of clinically significant A/A in AD patients, about factors influencing this course or about the variability of different outcome measures over time, such as the NPI or CMAI. This is even more evident for new scales such as the NPI-C. Findings from A3C will provide a better estimation of placebo group variability in trials, thus allowing for, more precise power estimates. Moreover, knowledge of the impact of demographic and other variables, such as vascular diseases or other NPS, on the trajectory of A/A overtime might improve the homogeneity of the sample population. In order to assess agitation response to treatment, three approaches have been used in clinical trials: 1) structured caregiver interviews (NPI-A/A, CMAI), 2) expert clinician scale ratings (NPI-C A/A), and 3) structured global ratings (modified ADCS-CGIC, CGI-C) based on judgment of experienced clinicians $(11,29)$. In order to complement NPS ratings based on caregiver report, clinical global ratings are used, since their strength is their being derived from experienced clinicians. A recent EU-US-CTAD Task Force (12) highlighted that choosing the best outcome measure for clinical trials was the key to treatment development for $\mathrm{A} / \mathrm{A}$ and proposed to use a combining clinician- and caregiver-derived outcome as primary efficacy outcome measure in absence of gold standard (12). In the meantime, this Task Force encouraged using existing datasets to construct an evidence-based single novel measure of agitation by selecting items subsets of existing scales. Data from the A3C study will help in answering this question and in moving forward the field.

The main limitation of $\mathrm{A} 3 \mathrm{C}$ is attrition of more than $30 \%$ during one year of follow-up. Attrition is common in cohorts of older adults, especially when patients are affected by a severe and progressive chronic disease such as $\mathrm{AD}$ (30). The $\mathrm{AD}$ patients from $\mathrm{A} 3 \mathrm{C}$ were notably and medically frail, and present a particularly severe complex form of disease with major complications such as distressing NPS and as consequence, with a higher risk of adverse outcomes that may explain this higher attrition compared with previous cohorts of $\mathrm{AD}$ patients. However, attrition during the three first months, the critical period of A3C study, was much lower $(<20 \%)$. The data of the attrition will also help for calculating sample size in future trials. The second limitation is that the diagnosis of $\mathrm{AD}$ was based on clinical criteria and there was no requirement for biomarker confirmation. Therefore, our population has a possible AD. The lumbar puncture was only performed in 23 patients (8.9\%); neither physio pathological biomarkers nor neuro- 
imaging biomarkers were performed in a standardized protocol since $\mathrm{A} 3 \mathrm{C}$ cohort was a usual care survey, and in general it is not clinical standard of care to assess AD biomarkers in a cohort with such advanced dementia as A3C.

The A3C study addresses a clinically important population, AD older patients with disruptive NPS, which are often under assessed and excluded from the research field. Thus, this study gives the opportunity if developing research in this vulnerable population. In addition, data from A3C study may improve clinical practice by better defining and measuring agitation and, consequently, by better targeting pharmacological and non-pharmacological treatments.

Little is known about the longitudinal course of clinically significant A/A in AD patients, about factors influencing this course or about the variability of different outcome measures over time, such as the NPI or CMAI, or the definition of a clinically meaningful improvement in these scales. This is even more evident for new scales such as the NPI-clinician rating. A3C study may provide useful data in order to improve clinical practice and to optimize future clinical trials of treatments for agitation symptoms in $\mathrm{AD}$.

Acknowledgments: L. Bories, A. Roustan, Y. Gasnier, S. Bordes, M.N. Cufi, F. Desclaux, Y. Gasnier, N. Gaits, M. Péré-Saun, S. Bordes.

Funding: The A3C cohort was supported by Ethypharm and Toulouse University Hospital.

Conflict of Interest: C. Lyketsos declares: 1) Grant support (research or CME) from NIH, Functional Neuromodulation, Bright Focus Foundation and 2) Payment as consultant or advisor from Avanir, Astellas, Roche, Karuna, SVB Leerink, Maplight, Axsome, Global Institute on Addictions. None conflict for the others authors.

Ethical Standards: A3C had ethical approval and oversight from the local Institutional Review Board (Toulouse University Hospital).

Open Access: This article is distributed under the terms of the Creative Commons Attribution 4.0 International License (http://creativecommons.org/ licenses/by/4.0/), which permits use, duplication, adaptation, distribution and reproduction in any medium or format, as long as you give appropriate credit to the original author(s) and the source, provide a link to the Creative Commons license and indicate if changes were made.

\section{References}

1. Cohen-Mansfield J. Conceptualization of agitation: results based on the Cohen-Mansfield agitation inventory and the agitation behavior mapping instrument. International Psychogeriatrics. 1996;8(Suppl 3):309-15.

2. Gonfrier S, Andrieu S, Renaud D, Vellas B, Robert PH. Course of neuropsychiatric symptoms during a 4-year follow up in the REAL-FR cohort. Journal of Nutrition Health Aging. 2012;16(2):134-7.

3. Kales HC, Lyketsos CG, Miller EM, Ballard C. Management of behavioral and psychological symptoms in people with Alzheimer's disease: an international Delphi consensus. International Psychogeriatrics. 2018; 31 (1): 83-90.

4. Selbaek G, Engedal K, Benth JS, Bergh S. The course of neuropsychiatric symptoms in nursing home patients with dementia over a 53-month followup period. International Psychogeriatrics. 2014; 26 (1):81-91.

5. Gonzalez-Salvador MT, Arango C, Lyketsos CG, Barba AC. The stress and psychological morbidity of the Alzheimer patient caregiver. International Journal of geriatric psychiatry. 1999; 14(9): 701-10.

6. Okura T, Plassman BL, Steffens DC, Llewellyn DJ, Potter GG, Langa KM. Neuropsychiatric symptoms and the risk of institutionalization and death: the aging, demographics, and memory study. Journal of American Geriatric Society. 2011;59(3):473-81.

7. Taragano FE, Allegri RF, Krupitzki H, et al. Mild behavioral impairment and risk of dementia: a prospective cohort study of 358 patients. Journal of Clinical
Psychiatry. 2009;70(4):584-92.

8. Peters ME, Schwartz S, Han D, et al. Neuropsychiatric symptoms as predictors of progression to severe Alzheimer's dementia and death: the Cache County Dementia Progression Study. American Journal of Psychiatry. 2015;172(5):460-

9. Costa N, Wubker A, de Mauleon A, et al. Costes of care of agitation associated with dementia in 8 European countries: results from the RighTimePlaceCare Study. Journal of American Medical Directors Association. 2018; 19 (1): 95 e1-e10.

10. Kales HC, Gitlin LN, Lyketsos CG. Assessment and management of behavioral and psychological symptoms of dementia. British Medical Journal. 2015; 350: h369.

11. Soto M, Andrieu S, Nourhashemi F, et al. Medication development for agitation and aggression in Alzheimer disease: Review and discussion of recent randomized clinical trial design. International Psychogeriatrics. 2014: $1-17$.

12. Sano M, Soto M, Carillo M, et al. Identifying better outcome measures to improve treatment of agitation in dementia: a report from the EU/US/CTAD Task Force. Journal of Prevention of Alzheimer's Disease. 2018; 5(2): 98-102.

13. Mueller SG, Weiner MW, Thal LJ, et al. Ways toward an early diagnosis in Alzheimer's disease: The Alzheimer's Disease Neuroimaging Initiative (ADNI). Alzheimer's \& Dementia: Journal of Alzheimer's Association. July 2005;1(1):55 66.

14. McKhann GM, Knopman DS, Chertkow H, et al. The diagnosis of dementia due to Alzheimer's disease: Recommendations from the National Institute on Aging-Alzheimer's Association workgroups on diagnostic guidelines for Alzheimer's disease. Alzheimers Dementia. 2011;7(3):263-9

15. Trzepacz PT, Saykin A, Yu P, et al. Alzheimer's Disease Neuroimaging Initiative. Subscale validation of the neuropsychiatric inventory questionnaire: comparison of Alzheimer's disease neuroimaging initiative and national Alzheimer's coordinating center cohorts. American Journal of Geriatric Psychiatry. 2013; 21:607-22.

16. Cummings J, Mintzer J, Brodaty H, et al. Agitation in cognitive disorders: International Psychogeriatric Association provisional concensus clinical and research definition. International Psychogeriatrics. 2015; 27(1):7-17

17. Cummings, JL, Mega M, Gray K, Rosenberg-Thompson S, Carusi DA, Gornbein J. The neuropsychiatric inventory: comprehensive assessment of psychopathology in dementia. Neurology, 1994. 44(12): p. 2308-14.

18. de Medeiros K, Robert P, Gauthier S, et al. The Neuropsychiatric InventoryClinician rating scale (NPI-C): reliability and validity of a revised assessmen of neuropsychiatric symptoms in dementia. International Psychogeriatrics. 2010; 22:984-994.

19. Schneider LS, Olin JT, Doody RS, et al. Validity and reliability of the Alzheimer's Disease Cooperative Study-Clinical Global Impression of Change. The Alzheimer's disease cooperative Study. Alzheimer disease Association Disorder. 1997; 11 Suppl 2:S22-32.

20. Drye LT, Ismail Z, Porsteinsson AP, et al., CitAD Research Group. Citalopram for agitation in Alzheimer's disease: design and methods. Alzheimers Dementia. 2012;8(2):121-30.

21. Guy W. ECDEU Assessment Manual for Psychopharmacology, revised. 1976 Bethesda, MD: US Department of Health, Education and Welfare.

22. Folstein MF, Folstein SE, McHugh PR. "Mini-Mental State": a practical method for grading the cognitive state of patients for the clinician. Journal of Psychiatric Research. 1975;12:196-8.

23. Katz S, Ford AB, Moskowitz RW, Jackson BA, Jaffe MW. Studies of illness in the aged. The index of ADL. A standardized measure of biological and psychological function. Journal of American Medical Association. 1963; 185: 914-19.

24. Sourdet S, Van Kan GA, Soto ME, et al. Prognosis of an abnormal one-leg balance in community-dwelling patients with Alzheimer's disease: a 2-year prospective study in 686 patients of the REAL.FR study. Journal of American Medical Director Association. 2012; 13(4): 407.

25. Logsdon R.G., Gibbons, LE, McCurry, SM and Terri, L. Quality of life in Alzheimer's disease: Patient and caregiver reports. Journal of Mental Health and Aging. 1999; 5(1), 21-32.

26. Wimo A, Nordber G. Validity and reliability of assessments of time. Comparisons of direct observations and estimates of time by the use of the Resource Utilisation in Dementia (RUD) -instrument. Archive of Gerontology and Geriatrics. 2007;44(1):71-81 (2007).

27. Anatchkova M, Brooks A, Swett L, et al. Agitation in patients with dementia: a systematic review of epidemiology and association with severity and course. International psychogeriatrics. 2019; 11:1-14.

28. Lyketsos CG, Lee HB. Diagnosis and treatment of depression in Alzheimer's disease. A practical update for the clinician. Dementias and Geriatric Cognitive Disorders. 2004; 17 (1-2): 55-64.

29. Soto M, Abushakra S, Cummings J, et al. Progression in treatment development for neuropsychiatric symptoms in Alzheimer's disease: focus on agitation and aggression. A report from the EU/US/CTAD Task Force. The journal of Prevention if Alzheimer's Disease. 2015; 2(3): 184-188.

30. Coley N, Gardette V, Toulza O, et al. Predictive factors of attrition in a cohor of Alzheimer disease patients. The REAL.FR study. Neuroepidemiology. 2008;31(2):69-79. 